\title{
Aqueous Biphase Extraction for Processing of Fine Coal
}

\author{
Grant No. DE-FG22-96 PC96211 \\ Semi-Annual Report
}

Reporting Period Start Date: 10/01/98

Reporting Period End Date: 04/01/99

Principal Author: K. Osseo-Asare, Professor of Metallurgy

Date Report was issued: 05/24/1999

DOE Award Number: DE-FG22-96 PC96211

Submitting organization: Metals Science and Engineering Program

Department of Materials Science and Engineering 209 Steidle Building

Penn State University

University Park, PA 16802 


\section{DISCLAIMER}

This report was prepared as an account of work sponsored by an agency of the United States Government. Neither the United States Government nor any agency thereof, nor any of their employees, makes any warranty, express or implied, or assumes any legal liability or responsibility for the accuracy, completeness, or usefulness of any information, apparatus, product, or process disclosed, or represents that its use would not infringe privately owned rights. Reference herein to any specific commercial product, process, or service by trade name, manufacturer, or otherwise does not necessarily constitute or imply its endorsement, recommendation, or favoring by the United States Government or any agency thereof. The views and opinions of authors expressed herein do not necessarily state or reflect those of the United States Government or any agency thereof. 


\section{DISCLAIMER}

Portions of this document may be illegible in electronic image products. Images are produced from the best available original document. 


\begin{abstract}
Ever-stringent environmental constraints dictate that future coal cleaning technologies be compatible with micron-size particle. This research program seeks to develop an advanced coal cleaning technology uniquely suited to micron-size particles, i.e., aqueous biphase extraction. The partitioning behaviors of alumina, hematite, silica, and titania were investigated. In the $\mathrm{pH}$ range of 2 to 12 , almost all of the alumina, hematite, and titania particles preferred the bottom phase because of the hydrophilic surfaces of these oxides. In contrast, silica particles transferred into the top phase, a result which is attributable to PEG adsorption on silica particles. Experiments conducted with oleic acid and hematite demonstrate that with the proper choice of collector, it is possible to transfer a previously hydrophilic particle into the top phase.
\end{abstract}




\section{TABLE OF CONTENTS}

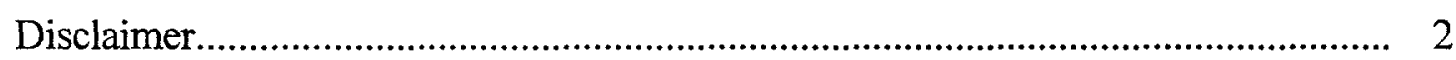

Abstract

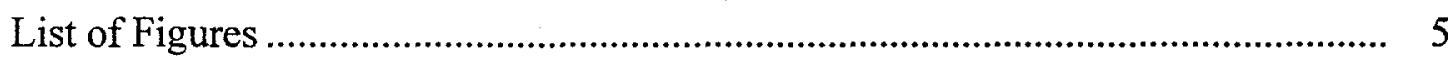

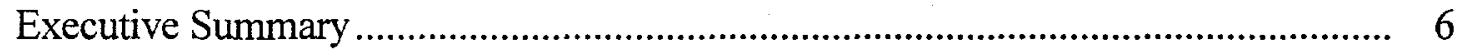

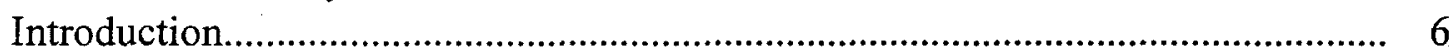

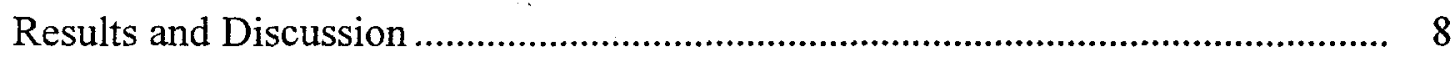

Summary and Conclusions ................................................................................. 10

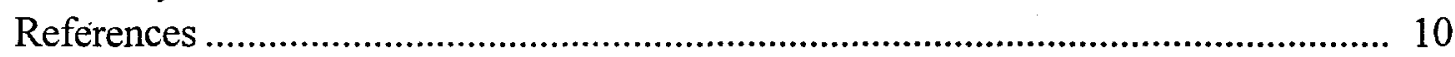




\section{LIST OF FIGURES}

Fig. 1 Yield of alumina, silica, and titania in the top phase of the PEG-2000/ $\mathrm{Na}_{2} \mathrm{SO}_{4} / \mathrm{H}_{2} \mathrm{O}$ system

Fig. 2 Effects of SDS and oleic acid on the partition of hematite in the PEG-4600/ $\mathrm{Na}_{2} \mathrm{SO}_{4} / \mathrm{H}_{2} \mathrm{O}$ system (SDS: $3.5 \times 10^{-4} \mathrm{M}$, oleic acid: $1 \times 10^{-4} \mathrm{M}$ )

Fig. 3 Effects of $\mathrm{pH}$ and oleic acid concentration on the top phase yield of ferric oxide in the PEG-4600/ $\mathrm{Na}_{2} \mathrm{SO}_{4} / \mathrm{H}_{2} \mathrm{O}$ system . 14

Fig. 4 Effects of pH and oleic acid concentration on the bottom phase yield of ferric oxide in the PEG- $4600 / \mathrm{Na}_{2} \mathrm{SO}_{4} / \mathrm{H}_{2} \mathrm{O}$ system 


\section{EXECUTIVE SUMMARY}

The objective of this research project is to develop an aqueous biphase extraction process for the treatment of fine coals. Aqueous biphase extraction is an advanced separation technology that relies on the ability of an aqueous system consisting of a water-soluble organic polymer and an inorganic salt to separate into two immiscible aqueous phases. Differences in the hydrophobic/hydrophilic properties of particulate can then be exploited to effect selective transfers to either the top polymer-rich phase, or the bottom salt-rich phase. The goal of this experimental program is to identify process conditions that optimize the selective transfer of coal into the top phase while retaining the mineral matter in the bottom phase. An additional goal is to develop an improved coal-pyrite separation technique based on aqueous biphase extraction.

The partitioning behavior of selected model oxides (alumina, hematite, silica and titania) in aqueous biphase systems and the effects of some surfactants were studied. For alumina, hematite, and titania, all particles stayed in the bottom phase in the $\mathrm{pH}$ range of 2 to 12 because of the hydrophilicity of these oxides. However, silica preferred the top phase during this $\mathrm{pH}$ range, which may be due to the adsorption of PEG on silica surface. The presence of oleic acid in the system can transfer hematite particles into the top phase in neutral or alkaline environments.

\section{INTRODUCTION}

Coal represents the largest source of fossil energy in the U.S. This resource also represents the most readily accessible and socially acceptable substitute for oil and natural gas. In response to the stipulations of the Clean Air Act (1), advanced coal cleaning technologies are needed in order to more efficiently eliminate unacceptable levels of ash and sulfur from the run-of-mine coal prior to combustion. The ability to achieve mineral matter liberation from coal is fundamental to all separation techniques that seek to produce super-clean coal. It has been concluded from the microscopic examination of a wide variety of U.S. coals that, in many cases, grinding to $10 \mu \mathrm{m}$ or below may be necessary in order to achieve the necessary liberation (2). It is clear, therefore, that future advanced coal cleaning technologies must be capable of accommodating micron size particles.

Large quantities of fine coals already exist in the rejects discharged into waste ponds. These fine coals are a result of the current highly mechanized production practices of continuous and longwall mining. As a result of the nonselectivity of cutting machines and the exploitation of higher ash/sulfur seams, these coal fines are characterized by high contents of mineral matter. These coal fines must therefore be cleaned in order to 
produce a salable product. Unfortunately, conventional coal cleaning techniques are not effective in treating such fine coals. The result is that large amounts of fine coals are discharged into refuse ponds, even though this material represents a potential source of energy. The proliferation of such waste ponds is no longer environmentally acceptable.

This project seeks to investigate the feasibility of separating pyrite and mineral materials from fine coal by using aqueous biphase extraction. Although aqueous biphase systems have been known for more than 100 years, it was only in the mid 1950s that their potential use as separation media was recognized. Albertsson who pioneered the separation of microbial cells, cell organelles, and virus (3) performed the initial work. In recent years, interest in aqueous biphase extraction has broadened to applications in the commercial-scale separation of proteins (5), as well as separation of metal ions (6), ultrafine particles (7), and organics (8). Chaiko et al. used aqueous biphase extraction to remove radioactive residue from soil $(4,9)$.

It is possible to form a two-phase system in certain polymer/inorganic salt/water mixtures. When the concentrations of the salt and polymer exceed certain limits, the aqueous system separates into two immiscible phases, in which the top phase is polymer-rich and the bottom phase is enriched in salt. Aqueous biphase extraction is very similar to conventional solvent extraction. Just like the organic solvent/water twophase systems, the top phase of the aqueous biphase system is more hydrophobic, and the bottom phase is more hydrophilic. The hydrophobic/hydrophilic character of the particle surface determines the partitioning of the particles into either the top more hydrophobic phase or the bottom more hydrophilic phase. Thus, differences in the surface chemistry of particles can be exploited for selective separations. It can be expected that the partitioning behavior of particles in aqueous biphase systems will also be significantly affected by surfactants because these reagents can change the surface properties of particles through adsorption.

Compared with conventional organic-solvent-based liquid-liquid extraction, aqueous biphase extraction is especially attractive for waste treatment applications, because it avoids the use of an organic solvent which itself is a possible pollutant. In addition, the polymers used in aqueous biphase systems are generally inexpensive, nontoxic, and biodegradable (7). The aqueous biphase systems can be recycled with the effective separation of particulates and solution. For separation of colloid particles, this process possesses another advantage compared with traditional separation processes such as flotation and flocculation because it does not have a low limit of particle size; it can even be used to separate metal ions (6).

In order to assess the applicability of this separation technology to fine particle processing, it is necessary to investigate the partitioning behavior of solid particles in aqueous biphase systems. From the partition experiments, it will be possible to identify 
conditions that favor the separation of particulate mixtures. This report focuses on the partitioning behavior of alumina, hematite, silica, and titania particles in polyethylene glycol (PEG)/salt/water aqueous biphase systems. The emphasis is on the effect of $\mathrm{pH}$. In the case of hematite, the effect of oleate addition is also investigated.

\section{RESULTS AND DISCUSSION}

\section{Partitioning Behavior of Alumina, Titania, and Silica}

The partitioning behaviors of alumina, titania, and silica in the PEG$2000 / \mathrm{Na}_{2} \mathrm{SO}_{4} / \mathrm{H}_{2} \mathrm{O}$ system are shown in Figure 1. In the $\mathrm{pH}$ range of 2 to 12, alumina and titania were confined to the bottom phase; however, almost all silica particles transferred into the top phase. It is well established that the surfaces of alumina and titania are covered by hydrophilic metal hydroxide groups. The particles then went into the bottom phase because of the hydrophilic surfaces. It is somewhat surprising, however, that silica partitioned into the top phase, although the $\mathrm{Si}$ atoms on silica also can be hydrolyzed to form Si-OH groups. The difference in the behavior of silica compared with the other oxides can be attributed to differences in their interactions with PEG. It is reported that PEG adsorbs on silica surface, with an adsorption density of about $0.6 \mathrm{mg} / \mathrm{m}^{2}$. In contrast, PEG adsorbs negligibly on hematite, alumina and titania (10-13).

It is known that PEG adsorbs on silica surface through hydrogen bonding between the $\mathrm{H}$ atom of the $\mathrm{Si}-\mathrm{OH}$ group and the $\mathrm{O}$ atom in the $\mathrm{PEG}$ chain. According to the geometry of the PEG chain, only half of the $O$ atoms can form hydrogen bonds $(13,14)$. The enthalpy change for PEG displacement of water on silica surface is about $9.9 \mathrm{kcal} / \mathrm{mol}$, a value that is typical for the formation energy of a hydrogen bond $(15,16)$. The neutral Si$\mathrm{OH}$ sites favor the adsorption of PEG (15). When Si-OH deprotonates to form Si-O'- the resulting negative site does not form a hydrogen bond with PEG because of the electrostatic repulsion between this site and the partial negative charge on the $O$ atom in the PEG chain. It is reported that the flotation of silica with PEG decreased above about $\mathrm{pH} 6$ because of the desorption of PEG from silica surface (17). This desorption process was attributed to the electrostatic repulsion between the polymer and the solid. Similar reasoning accounts for the decline in the yield above $\mathrm{pH} 10$.

\section{Effects of Surfactants on the Partitioning Behavior of Hematite}

Effects of SDS and Xanthate. Figure 2 shows the partitioning behavior of hematite particles in the PEG- $4600 / \mathrm{Na}_{2} \mathrm{SO}_{4} / \mathrm{H}_{2} \mathrm{O}$ system and the corresponding effects of SDS (sodium dodecyl sulfate, $\left.3.5 \times 10^{-4} \mathrm{M}\right)$ and xanthate $\left(1 \times 10^{-3} \mathrm{M}\right)$. In all cases, almost all the particles stayed in the bottom phase and there was minimal transfer to the top phase and the interface. On the surface of ferric oxide particles, the - $\mathrm{FeOH}$ groups combine with protons in solution to form protonated $-\mathrm{FeOH}_{2}^{+}$groups at low $\mathrm{pH}$ (below the $\mathrm{pzc}$ of $\sim 8.5$ ); 
the $-\mathrm{FeOH}$ groups deprotonate into $-\mathrm{FeO}^{-}$groups when the $\mathrm{pH}$ is higher than the pzc. These surface groups are all hydrophilic. Thus, it is not surprising that all the ferric oxide particles stayed in the bottom phase under all $\mathrm{pH}$ conditions. When the surfactants SDS and xanthate were introduced into the system, the partitioning behavior of ferric oxide did not change significantly. It is well known that SDS and xanthate can be adsorbed physically on the ferric oxide surface. However, in this system, the concentration of polymer and salt is so high that the surface of ferric oxide is fully covered by ions, which inhibited the adsorption of SDS and xanthate on the surface. Adding SDS and xanthate, therefore, changed the surface of ferric oxide negligibly, so that the partition of ferric oxide remained the same.

Effect of Oleate. Figures 3 and 4 show respectively the yield of hematite particles in the top and bottom phases of the PEG-4600/ $\mathrm{Na}_{2} \mathrm{SO}_{4} / \mathrm{H}_{2} \mathrm{O}$ system in the presence of oleate. Below pH 6, addition of oleate had no effect on the partitioning behavior of hematite. However, above this $\mathrm{pH}$, there was a dramatic increase in the yield in the top phase; particles transferred to the top phase at about $\mathrm{pH} 6$, and the yield reached a maximum. With further $\mathrm{pH}$ increase, the yield began to decrease; the decrease was less pronounced as oleate concentration increased from $5 \times 10^{-5} \mathrm{M}$ to $2 \times 10^{-4} \mathrm{M}$.

Oleate can be used as a collector for hematite in the froth flotation process (18-22) and it is reported that this reagent adsorbs chemically on hematite $(23,24)$. According to the work of Han, Healy, and Fuerstenau (24), when the concentration of oleate exceeded about $2.5 \times 10^{-5} \mathrm{M}$, there was marked adsorption, even at the pzc of 8.5 . The flotation recovery of ferric oxide in the presence of oleate decreased at low $\mathrm{pH}$; this phenomenon is presumably due to the precipitation of undissociated oleate. The dissociation constant of oleate is known to be approximately $10^{-5}(25)$, which means ionization becomes significant only above $\sim \mathrm{pH} 5$. Ofor (21) found that the adsorption density of oleate on hematite particles showed a peak at about $\mathrm{pH}$ 7. Below $\mathrm{pH} \mathrm{7,} \mathrm{the} \mathrm{adsorption} \mathrm{density}$ decreased rapidly. The adsorption density decreased slowly between $\mathrm{pH}$ 7-9 and decreased sharply above $\mathrm{pH} 9$.

It is reasonable to assume that the adsorption behavior of oleate in aqueous biphase systems is similar to the situation in froth flotation systems (18-24). At low $\mathrm{pH}$, the undissociated oleate predominates and it can only physically adsorb on the surface of ferric oxide (26). Because of the high ionic strength in the aqueous biphase system, the adsorption of undissociated oleate is expected to be low. Accordingly, the hematite surface remained hydrophilic and the particles stayed in the bottom phase. At higher $\mathrm{pH}$, when the dissociated oleate became increasingly available, the chemisorption of the organic reagent made the hematite surface hydrophobic. This effect facilitated particle transfer into the top phase. As the $\mathrm{pH}$ exceeded the pzc of hematite, the surface became negatively charged. There was electrostatic repulsion between the particles and oleate because of the negatively charged dissociated carboxylic acid group of the reagent. The 
adsorption density of oleate on the hematite particles then decreased and this, in turn, led to a drop in the yield.

\section{SUMMARY AND CONCLUSIONS}

This study, extending the aqueous biphase extraction technology to metal oxides, demonstrates that $\mathrm{pH}$ adjustment and surfactant addition can be used effectively to control particle partitioning behavior in aqueous biphase systems. The partitioning behaviors of alumina, hematite, silica, and titania were investigated. In the $\mathrm{pH}$ range of 2 to 12 , almost all of the alumina, hematite, and titania particles preferred the bottom phase because of the hydrophilic surfaces of these oxides. In contrast, silica particles stayed in the top phase, a result which is attributable to PEG adsorption on silica particles. In the presence of SDS and xanthate, the partitioning behavior of hematite remained unchanged, a result of the physical nature of the adsorption of these reagents. The experiments conducted with the oleic acid and hematite demonstrate that with the proper choice of collector (i.e., one which chemisorbs), it is possible to transfer a previously hydrophilic particle into the top phase.

\section{REFERENCES}

1. Asst. Sec. of State for Fossil Energy, U. S. Department of Energy, Clean Coal Technology: The New Coal Era, June, 1990

2. M. J. Mankosa, G. T. Adel, and R. H. Yoon, Powder Tech., 1986, 49: 75

3. P. A. Albertsson, Partition of Cell Particles and Macromolecules, 3rd. ed., WileyInterscience: New York, 1986

4. D. J. Chaiko, R. Mensah-Biney, C. J. Mertz and A. Rollins, Sep. Sci. Technol., 1993, 28: 765

5. H. Walter, D. E. Brooks and D. Fisher Eds., Partitioning in Aqueous Two-Phase Systems, Academic Press: New York, 1985

6. R. D. Rogers, A. H. Bord and C. B. Bauer, Sep. Sci. Technol., 1993, 28: 1091

7. K. P. Ananthapadmanabhan and E. D. Goddard, Process for the Separation of Solid Particulate Matters, U. S. Patent 47,225,358, 1987

8. D. J. Chaiko et al., in Proceeding $14^{\text {th }}$ Annual Army Environmental R\&D Symposium, USATHAMA Report CETHA-TE-TR-90055, p. 305, 1989

9. D. J. Chaiko, Y. Vojta and M. Takeuchi, Sep. Sci. Technol., 1995, 30: 1123

10. J. Eisenlauer, E. Killmann, and M. Korn, J. Colloid Interface Sci., 1980, 74:120

11. P. Trens and R. Denoyel, Langmuir, 1993, 9:519

12. M. R. Bohmer, L. K. Koopal, and R. Janssen, Langmuir, 1992, 8:2228

13. W. J. Walker, J. S. Reed, S. K. Verma and W.E. Zirk, J. Am. Ceram. Soc., 1999, $82: 585$ 
14. E. Koksal, R. Ramachandran, P. Somasundaran, and C. Maltesh, Powder Tech., 1990, 62:253

15. A. Gellan and C. H. Rochester, J. Chem. Soc., Faraday Trans. 1, 1985, 81:3109

16. E. Killmann, Polymer, 1976, 17:864

17. J. Rubio and J. A. Kitchener, J. Colloid Interface Sci., 1976, 57:132

18. M. C. Fuerstenau, R. W. Harper, and J. D. Miller, Trans. AIME, 1970, 247:69

19. I. Iwasaki, S. R. B. Cooke, and H. S. Choi, Trans. AIME, 1960, 217:237

20. O. Ofor, J. Colloid Interface Sci., 1996, 179:323

21. O. Ofor, J. Colloid Interface Sci., 1995, 174:345

22. R. D. Pasco and E. Doherty, Int. J. Miner. Proc., 1997, 51:269

23. D. W. Fuerstenau and T. W. Healy, in Adsorption Bubble Separation Techniques, R. Lemlich ed., Academic Press, New York, 1972

24. K. N. Han, T. W. Healy, and D. W. Fuerstenau, J. Colloid Interface Sci., 1973, 44:407

25. I. Iwasaki and P. L. deBruyn, J. Phys. Chem., 1958, 62:594

26. K. Ananthapadmanabhan, P. Somasundaran, and T. W. Healy, Trans. AIME, 1980, 266:2003 


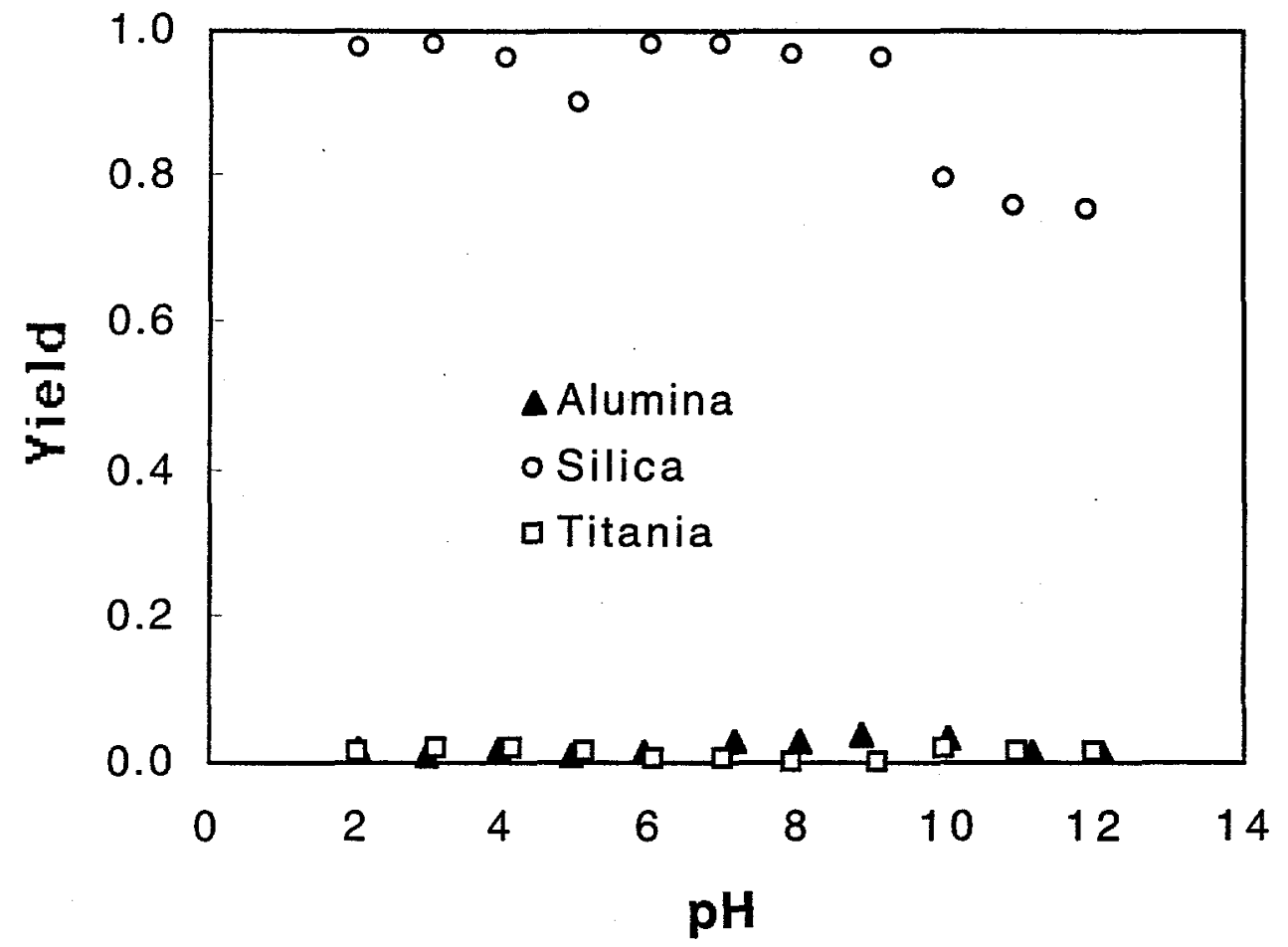

Figure 1. Yield of alumina, silica, and titania in the top phase of the PEG$2000 / \mathrm{Na}_{2} \mathrm{SO}_{4} / \mathrm{H}_{2} \mathrm{O}$ system. 


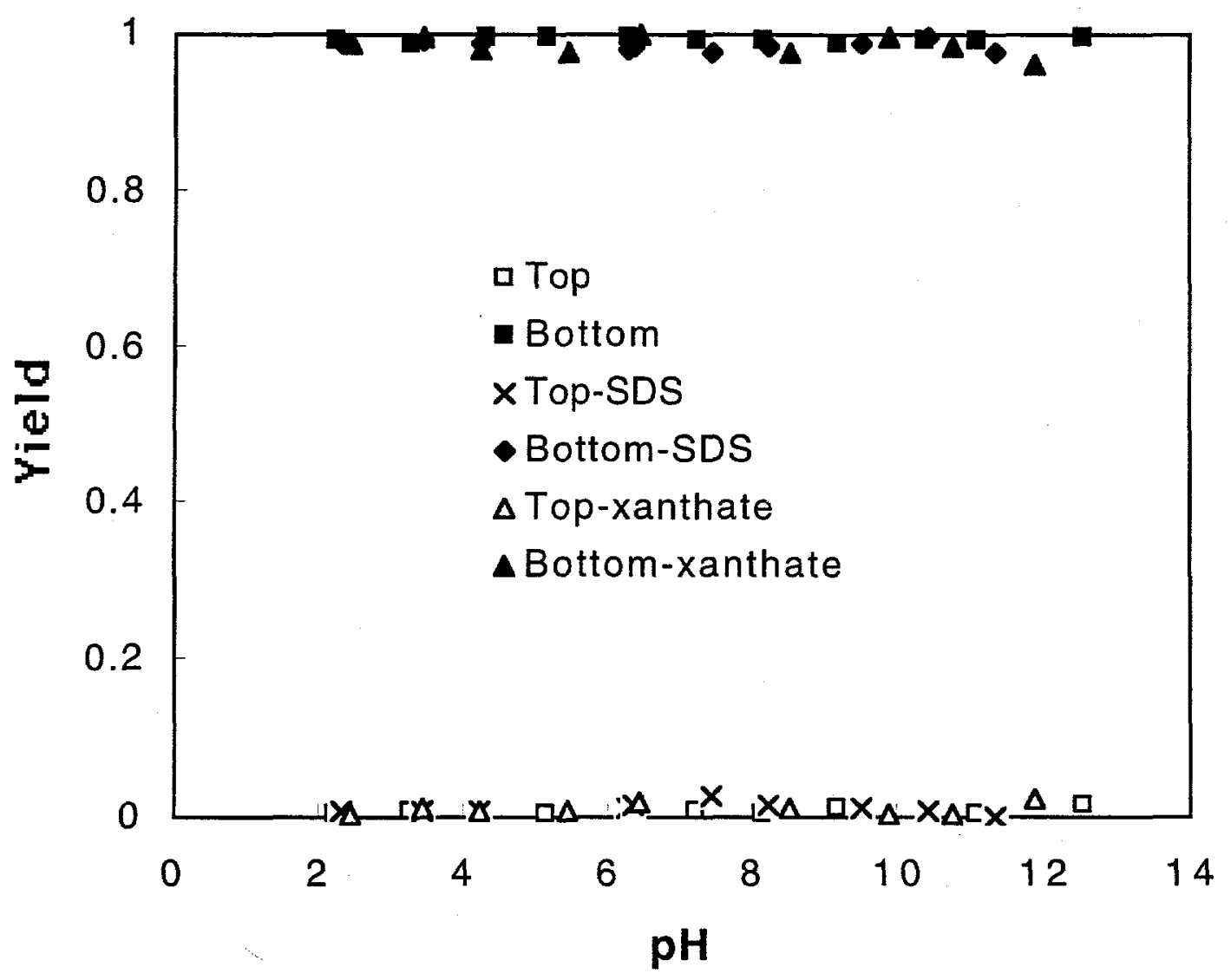

Figure 2. Effects of SDS and xanthate on the partition of hematite in the PEG$4600 / \mathrm{Na}_{2} \mathrm{SO}_{4} / \mathrm{H}_{2} \mathrm{O}$ system (SDS: $3.5 \times 10^{-4} \mathrm{M}$, xanthate: $1 \times 10^{-3} \mathrm{M}$ ). 


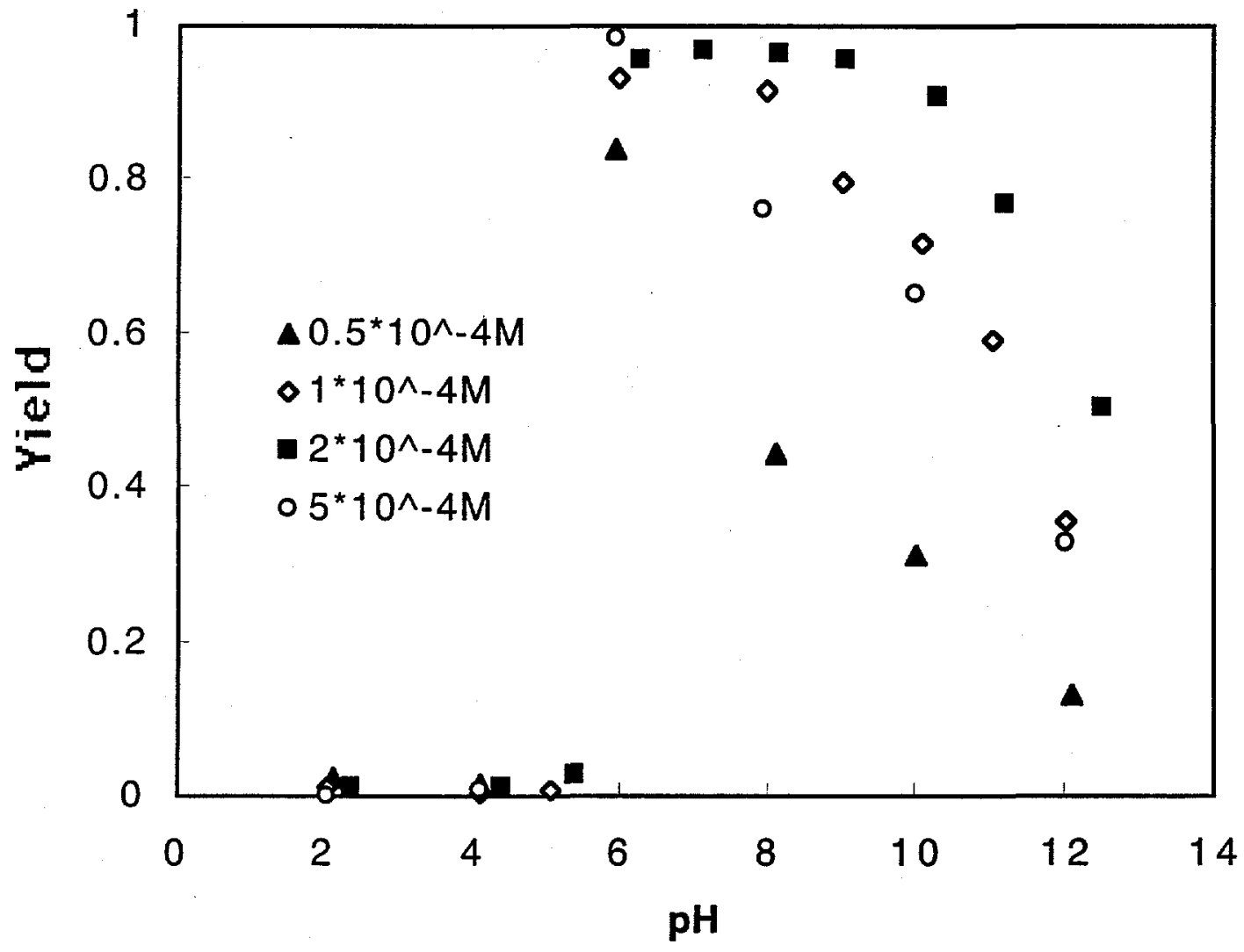

Figure 3. Effects of $\mathrm{pH}$ and oleic acid concentration on the top phase yield of hematite in the PEG- $4600 / \mathrm{Na}_{2} \mathrm{SO}_{4} / \mathrm{H}_{2} \mathrm{O}$ system. 


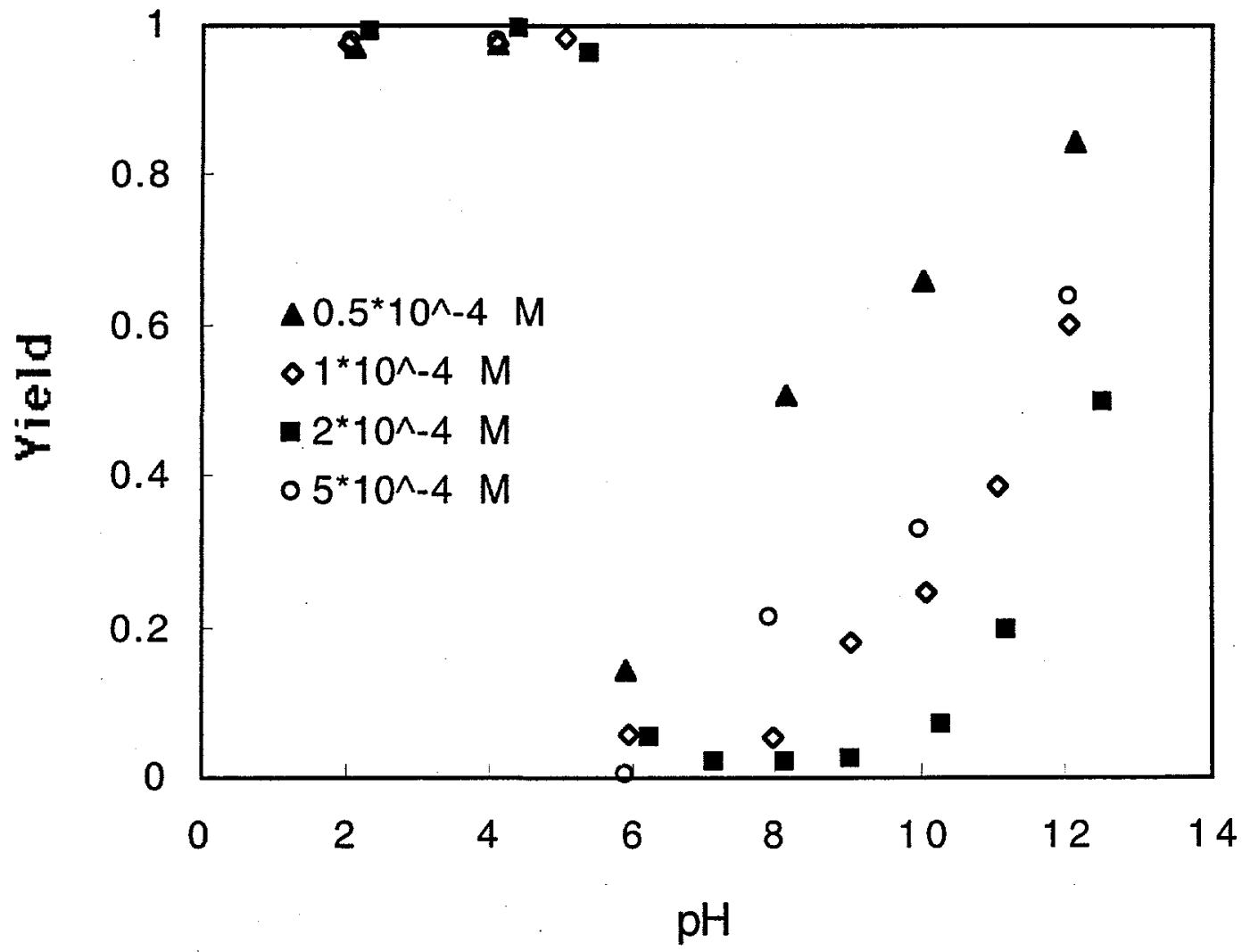

Figure 4. Effects of $\mathrm{pH}$ and oleic acid concentration on the bottom phase yield of hematite in the PEG-4600/ $\mathrm{Na}_{2} \mathrm{SO}_{4} / \mathrm{H}_{2} \mathrm{O}$ system. 